\title{
Referential calls coordinate multi-species mobbing in a forest bird community
}

\author{
Toshitaka N. Suzuki ${ }^{1}$
}

Received: 28 September 2015/Accepted: 23 October 2015/Published online: 6 November 2015

(C) Japan Ethological Society and Springer Japan 2015

\begin{abstract}
Japanese great tits (Parus minor) use a sophisticated system of anti-predator communication when defending their offspring: they produce different mobbing calls for different nest predators (snake versus non-snake predators) and thereby convey this information to conspecifics (i.e. functionally referential call system). The present playback experiments revealed that these calls also serve to coordinate multi-species mobbing at nests; snakespecific mobbing calls attracted heterospecific individuals close to the sound source and elicited snake-searching behaviour, whereas non-snake mobbing calls attracted these birds at a distance. This study demonstrates for the first time that referential mobbing calls trigger different formations of multi-species mobbing parties.
\end{abstract}

Keywords Birds $\cdot$ Mobbing calls $\cdot$ Multi-species mobbing $\cdot$ Playback experiment $\cdot$ Referential signal

\section{Introduction}

Upon encountering a predator, prey need to choose an appropriate anti-predator strategy (Caro 2005). One typical strategy is to escape from a predator and seek safety to avoid predation (Cooper and Blumstein 2015). Another strategy is to mob a predator, where prey individuals cooperatively approach and harass the predator with intensive behavioural displays, typically driving it away

Toshitaka N. Suzuki

toshi.n.suzuki@gmail.com

1 Department of Evolutionary Studies of Biosystems, The Graduate University for Advanced Studies (SOKENDAI), Hayama 240-0193, Kanagawa, Japan from the vicinity (Curio 1978). Mobbing has been reported in many animal taxa, such as fish (Dominey 1983), birds (Curio 1978), and mammals (Tamura 1989; Graw and Manser 2007). In forest birds, mobbing often involves individuals from multiple species that share the same predators (Sieving et al. 2004), and this may be facilitated by the attraction to mobbing calls produced by initiators (Hurd 1996; Forsman and Mönkkönen 2001; Templeton and Greene 2007; Nolen and Lucas 2009; Randler and Förschler 2011; Randler and Vollmer 2013; Wheatcroft and Price 2013). Since mobbing as a large group is more effective than mobbing as a small group (Flasskamp 1994; Krams et al. 2009), interspecific attraction to mobbing calls would help provide a mutual benefit for both initiators and attendees in reducing their predation risk.

While most of these studies have focussed on the context of self-defence, multi-species mobbing also occurs in the context of brood defence, where parents produce repeated mobbing calls and harass a nest predator (Caro 2005). Although these calls may carry a cost of attracting additional nest predators to the nests (Krama and Krams 2005), parents may reduce the immediate risk of nest predation by eliciting appropriate anti-predator reactions in receivers (Magrath et al. 2010). Like mobbing as self-defence, grouping can increase the efficacy of defence against nest predators (Robinson 1985; Krams et al. 2009; Campobello et al. 2011) and mobbing calls may serve to facilitate the attraction of other species to the nests. However, there is a lack of studies on the influence of mobbing calls on the formation of multi-species mobbing at nests.

In this study, I investigated the response of forest birds to heterospecific mobbing calls produced in the context of brood defence. Japanese great tits (Parus minor) use a sophisticated system of anti-predator communication that 
distinguishes different nest predators with acoustically distinct mobbing calls. The tits produce "jar" calls specifically for snakes and "chicka" calls for other predators such as crows and martens (Suzuki 2011, 2014). These calls transmit sufficient information about the type of nest predator (snakes versus non-snake predators) to both parents (Suzuki 2012a, 2015) and nestlings (Suzuki 2011) and, therefore, are considered as functionally referential signals (Gill and Bierema 2013). Such information may also be detected by other species breeding within the same habitat as Japanese great tits (see Magrath et al. 2015a). I played back the two types of mobbing calls near the nests of great tits in the absence of actual predators and recorded the behavioural responses of heterospecific species.

\section{Materials and methods}

\section{Study site and subjects}

I conducted the experiments at 14 separated sites (at least $250 \mathrm{~m}$ apart) in a mixed deciduous-coniferous forest in Karuizawa, Nagano, Japan $\left(36^{\circ} 21-22^{\prime} \mathrm{N}, 138^{\circ} 35-36^{\prime} \mathrm{E}\right)$ where nest boxes of Japanese great tits were located (attached to tree trunks $1.8 \mathrm{~m}$ from the ground) for their first broods of the season. In this forest, many species of forest birds were observed to breed within the same habitat as Japanese great tits (Table 1). Notably, coal and willow tits were abundant in the forest and were observed in all experimental sites. Most species were observed to carry food items to their nests, indicating that they were caring for nestlings. Long-tailed tits started breeding earlier than other species, and were observed to form family groups and provide food to fledglings. In addition to these resident species, there were some migratory species, such as brown flycatchers and narcissus flycatchers, breeding in the same forest.

\section{Experimental procedure}

I tested the response of heterospecific species of birds to playbacks of "chicka" calls, "jar" calls, and background noise (control). Playback stimuli were constructed by using recordings of "chicka" calls from 10 individuals (six males and four females) and those of "jar" calls from nine individuals (five males and four females). For each mobbing call playback, five calls were chosen from the same individual, and these calls were repeated to fill a 3-min sound file at a rate of 5 calls $/ 12 \mathrm{~s}$ (roughly one call every $2.4 \mathrm{~s}$ ). This calling rate was within the range of natural repetition rates for both "chicka" and "jar" calls at the early nestling stage (Suzuki 2012a). Low-frequency $(<1 \mathrm{kHz})$ noise was filtered out and the calls were amplified on a computer. Background noise files were created in the same way as the call files. Sound editing was conducted using Adobe Audition 3.0 software (Adobe Corporation, San Jose, CA, USA) and more detailed information has been provided elsewhere (Suzuki 2012a). Unique exemplars were used for each trial in order to avoid pseudoreplication.

Table 1 Total number of individuals and trials in which individuals approach within $10 \mathrm{~m}$ of a speaker during playbacks of "chicka" and "jar" calls

\begin{tabular}{|c|c|c|c|c|}
\hline \multirow[t]{2}{*}{ Species } & \multicolumn{2}{|l|}{ Chicka } & \multicolumn{2}{|l|}{ Jar } \\
\hline & Number of individuals & Number of trials & Number of individuals & Number of trials \\
\hline Coal tit (Periparus ater) $)^{\mathrm{a}, \mathrm{c}}$ & 2 & 1 & 7 & 4 \\
\hline Willow tit (Poecile montanus) $)^{\mathrm{a}, \mathrm{c}}$ & 3 & 3 & 3 & 3 \\
\hline Long-tailed tit (Aegithalos caudatus) $)^{\mathrm{a}, \mathrm{d}}$ & 0 & 0 & 3 & 1 \\
\hline Nuthatch (Sitta europaea) $)^{\mathrm{a}, \mathrm{c}}$ & 0 & 0 & 3 & 2 \\
\hline Japanese white eye (Zosterops japonicus) $)^{\mathrm{a}, \mathrm{c}}$ & 0 & 0 & 5 & 3 \\
\hline Meadow bunting (Emberiza cioides) $)^{\mathrm{a}, \mathrm{c}}$ & 0 & 0 & 1 & 1 \\
\hline Brown flycatcher (Muscicapa dauurica) ${ }^{\mathrm{b}, \mathrm{c}}$ & 0 & 0 & 1 & 1 \\
\hline Narcissus flycatcher (Ficedula narcissina) ${ }^{\mathrm{b}, \mathrm{c}}$ & 1 & 1 & 1 & 1 \\
\hline Brown-eared bulbul (Hypsipetes amaurotis) ${ }^{\mathrm{a}, \mathrm{c}}$ & 2 & 2 & 3 & 3 \\
\hline Japanese pygmy woodpecker (Dendrocopos kizuki) ${ }^{\mathrm{a}, \mathrm{c}}$ & 0 & 0 & 2 & 2 \\
\hline \multicolumn{5}{|l|}{${ }^{a}$ Resident species } \\
\hline \multicolumn{5}{|l|}{ b Immigrant species } \\
\hline \multicolumn{5}{|l|}{${ }^{\mathrm{c}}$ Nestling period } \\
\hline d Post-fledgling period & & & & \\
\hline
\end{tabular}


Experiments were carried out from 3 June to 16 June 2011 when great tit nestlings were 6-9 days old. An ATSPG50 speaker (Audio-Technica Corporation, Tokyo, Japan) was hung from a tree and fixed $1.6 \pm 0.2 \mathrm{~m}$ from the ground and $4.8 \pm 0.6 \mathrm{~m}$ from the nest box (mean $\pm \mathrm{SD}, n=14$ ). The playback speaker was connected to an R-09 HR digital audio recorder (Roland Corporation, Shizuoka, Japan) using EXC-12A extension cords (Victor Company of Japan, Kanagawa, Japan), which enabled the control of playbacks from an observation position $15 \mathrm{~m}$ away from the nest. Playbacks commenced when a pair of great tits was within $5 \mathrm{~m}$ of the nest and neither bird was vocalizing, in order to control for the effect of the presence of the tits on the behaviour of heterospecific individuals. Mobbing calls were played back at a constant volume $(75 \mathrm{~dB}$ at $1 \mathrm{~m})$, and background noise was played back at the same amplitude as the background noise level of the call playbacks $(50 \mathrm{~dB}$ at $1 \mathrm{~m})$. All three stimuli ("chicka" calls, "jar" calls, and background noise) were tested at each nest. Each trial was separated by at least $2 \mathrm{~h}$ to reduce habituation (see also Suzuki 2012a). The order of the playbacks was randomized. The speaker position was fixed for all treatments at each site in order to control its possible effect on responses. Trials were conducted in calm, dry weather between 0830 and $1600 \mathrm{~h}$ (Japan Standard Time).

During the 3 min of playbacks, I counted the number of species and individuals that approached the playback speaker. In order to assess the intensity of the approaching response, I prepared three different thresholds of distance from a speaker: 3,5 , and $10 \mathrm{~m}$. I also recorded whether birds gazed at the ground during trials, which was defined as occurring when birds looked towards the ground and pointed their bills in the same direction while raising their tails above their heads (see Suzuki 2012a).

\section{Statistical analysis}

All statistical tests were performed using R 3.1.2 (R Core Team 2014) and its packages. Multinomial logistic regression ('multinom' function in the package 'nnet') was used to examine whether the composition of species that approached the speaker differed according to the experimental site or playback call types. I included the species of individual birds as dependent variables, and the experimental site and treatments ("chicka" or "jar") as independent variables. Non-parametric statistics were used to compare the intensity of approaching behaviour. Friedman's test ('friedman.test' in 'stats') was used for the primary analysis; exact Wilcoxon matched-pairs signedrank tests ('wilcox.exact' in 'exactRankTests') were used for the post hoc analyses because of the small sample size
(Mundry and Fischer 1998). I used a Fisher's exact probability test ('fisher.test' in 'stats') to investigate whether the performance of gazing behaviour was affected by the type of playback calls. All tests were two-tailed, and the significance level was set at $\alpha=0.05$. Although my analyses involved multiple comparisons of responses, I did not adjust the significance level as the smaller number of samples increases the probability of making type II errors (Nakagawa 2004).

\section{Results}

A total of 10 species of birds were observed within $10 \mathrm{~m}$ of the playback speaker during the 3 min of experimental trials (Table 1). Birds from species in the family Paridae were the most common among those that approached mobbing calls of Japanese great tits (coal tits: $7 \%$ of "chicka" call trials and $29 \%$ of "jar" call trials; willow tits: $21 \%$ of "chicka" call trials and $21 \%$ of "jar" call trials). No predator species were observed during any playback trials. A multinomial logistic regression showed that the composition of heterospecific species that approached within $10 \mathrm{~m}$ of the speaker was significantly affected by the playback site $\left(\chi^{2}=19.01, p=0.014\right)$, but not by the call type $\left(\chi^{2}=13.84, p=0.086\right)$.

Birds approached differently in response to "chicka" and "jar" calls (Fig. 1; Table 2). During the playback of "chicka" calls, more heterospecific species were observed within $10 \mathrm{~m}$ of the speaker than during the control playback of background noise. However, there were no significant tendencies for birds to approach to within $5 \mathrm{~m}$ of the speaker during "chicka" calls. The playback of "jar" calls attracted more species than the playback of "chicka" calls. In particular, birds approached within $3 \mathrm{~m}$ of the speaker when hearing "jar" calls. None of the heterospecific species were attracted to the speaker during the playback of background noise. Such differences in approaching behaviour were detected even when analysing the heterospecific response as the total number of individuals (Table 2 ).

The playback of "jar" calls also elicited a downward gazing response in several species of birds; coal tits $(n=4$ trials), willow tits $(n=3)$, long-tailed tits $(n=1)$, nuthatches $(n=2)$, and Japanese white eyes $(n=3)$ always gazed at the ground when approaching "jar" calls. In contrast, such a response was not observed even when these species approached the playback of "chicka" calls (coal tit: $n=1$; willow tit: $n=3$ ). When pooling the data for coal and willow tits, there was a significant effect of call type on the occurrence of gazing behaviour (Fisher' exact test, $p=0.003$ ). 
$<3 \mathrm{~m}$
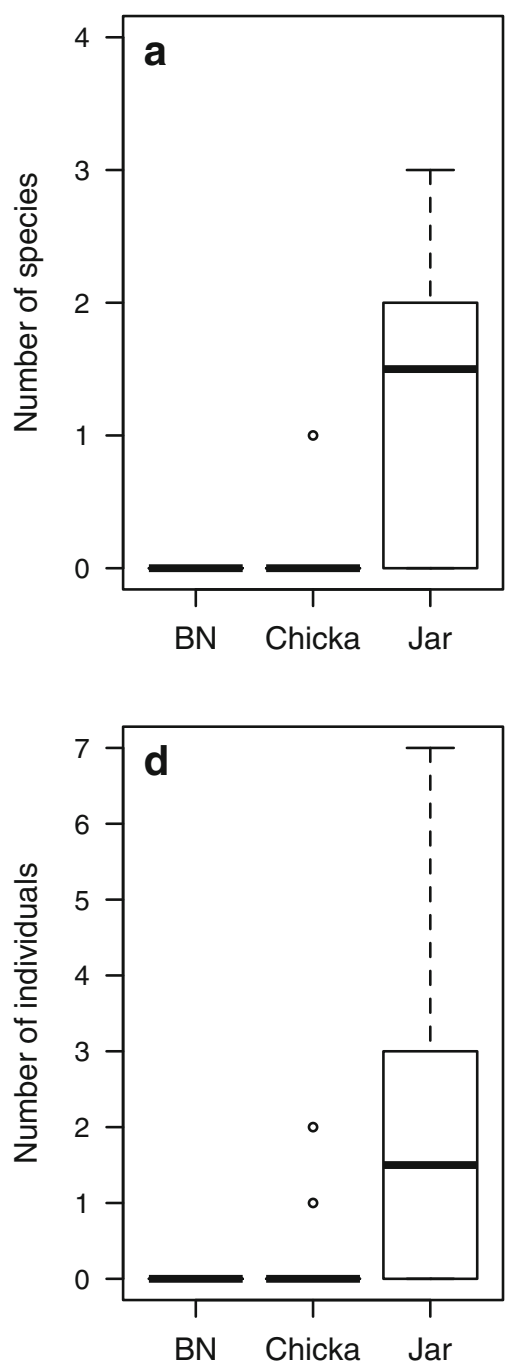

$<5 \mathrm{~m}$
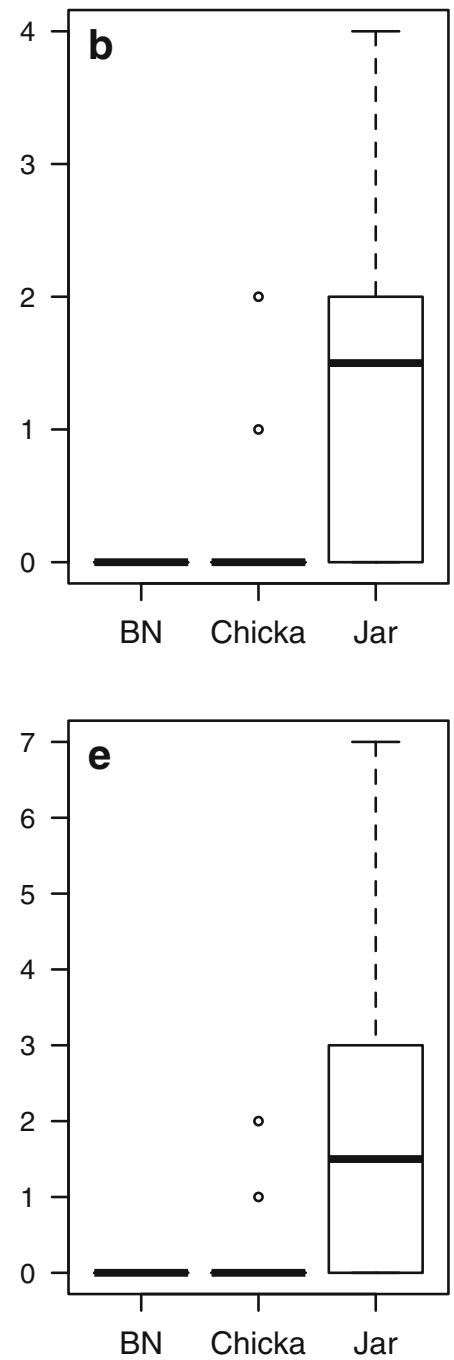

$<10 \mathrm{~m}$
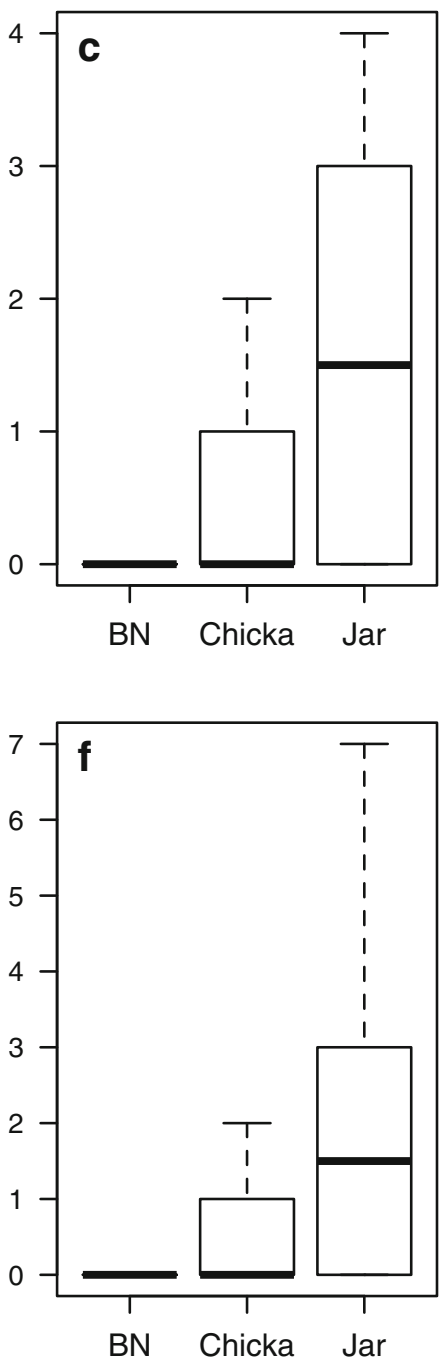

Fig. 1 Interspecific attraction to two types of mobbing calls of Japanese great tits ("chicka" and "jar") and a background noise control (BN), as shown by the number of species $(\mathbf{a}-\mathbf{c})$ and individuals $(\mathbf{d}-\mathbf{f})$ that approached a speaker during 3-min of playbacks

\section{Discussion}

Birds approached playbacks of both types of mobbing calls, but their responses were different between the types of mobbing calls. They approached more closely to the playback of "jar" calls than to the playback of "chicka" calls. Since the composition of species that approached within $10 \mathrm{~m}$ of the speaker did not differ between these call treatments, these individuals adjusted their response according to the type of mobbing call. These results demonstrate for the first time that different types of mobbing calls trigger different formations of multi-species mobbing parties.

In addition to the approaching behaviour, individuals of some species gazed at the ground when hearing "jar" calls. This response has been described as a typical reaction of
Japanese great tits to "jar" calls (Suzuki 2012a), which serves to search for a snake that approaches nests from the ground (Suzuki and Ueda 2013). Such gazing behaviour was observed not only in closely related species of Japanese great tits, such as coal and willow tits, but also in phylogenetically distant species such as long-tailed tits, nuthatches, and Japanese white eyes. However, a gazing response was never observed during the playback of "chicka" calls. These results suggest that heterospecific species derive referential information about snakes from snake-specific "jar" calls.

Although my results show that several birds respond appropriately to different mobbing calls of Japanese great tits, it remains unclear how they acquire this ability. In my study site, many bird species live in mixed-species flocks with Japanese great tits before their breeding season 
Table 2 Results of statistical analyses of interspecific attraction to the three playback treatments: "chicka" calls, "jar" calls, and background noise $(\mathrm{BN})$

\begin{tabular}{|c|c|c|c|c|c|}
\hline \multirow[t]{2}{*}{ Variables } & \multicolumn{2}{|c|}{ Primary test ${ }^{\mathrm{a}}$} & \multicolumn{3}{|c|}{ Post-hoc $^{\mathrm{b}}(p)$} \\
\hline & $\overline{\chi^{2}}$ & $p$ & Chicka-BN & Jar-BN & Chicka-jaı \\
\hline \multicolumn{6}{|c|}{ Number of species } \\
\hline $3 \mathrm{~m}$ & 12.18 & 0.002 & 0.5 & 0.004 & 0.011 \\
\hline $5 \mathrm{~m}$ & 12.24 & 0.002 & 0.25 & 0.004 & 0.034 \\
\hline $10 \mathrm{~m}$ & 10.29 & 0.006 & 0.031 & 0.004 & 0.052 \\
\hline \multicolumn{6}{|c|}{ Number of individuals } \\
\hline $3 \mathrm{~m}$ & 12.18 & 0.002 & 0.5 & 0.004 & 0.023 \\
\hline $5 \mathrm{~m}$ & 12.24 & 0.002 & 0.25 & 0.004 & 0.051 \\
\hline $10 \mathrm{~m}$ & 10.29 & 0.006 & 0.031 & 0.004 & 0.067 \\
\hline
\end{tabular}

Statistically significant $p$ values $(<0.05)$ are shown in bold

a Friedman's test

${ }^{\mathrm{b}}$ Exact Wilcoxon signed-rank test

(Suzuki 2012b) and breed using the same habitat as the tits. Therefore, birds may have opportunities to learn to associate heterospecific mobbing calls with predatory threats, and this may contribute to the rapid spread of anti-predator behaviour within a bird community (Wheatcroft and Price 2013; Magrath et al. 2015b). However, it is also possible that interspecific responses to mobbing calls are genetically inherited. Support for this idea comes from previous studies showing that several birds respond appropriately to the mobbing calls of allopatric species when they first hear these calls (Johnson et al. 2003; Randler 2012). To test these possibilities, it would be worthwhile to conduct additional playback experiments in other bird communities where Japanese great tits are absent.

The present findings raise an interesting question for further studies: how do birds benefit from helping the brood defence of other species? It might be that birds approached the mobbing calls on the basis of interspecific reciprocity (Krams and Krama 2002; Campobello et al. 2011), which could be tested by exploring the response of Japanese great tits to the mobbing calls of neighbour species. It is also possible that birds benefit from mutualism in that they cooperatively prevent predators from learning to view the avian nests as a profitable food source, providing a new hypothesis for the adaptive functions of avian mobbing (Curio 1978). Furthermore, the benefits from approaching heterospecific mobbing calls could differ among species. For example, migratory birds may not have enough knowledge about predators in a breeding site, and therefore may approach the mobbing calls of resident species in order to gather information (Nocera et al. 2008). Future research may provide new insight into the adaptive value of the recognition of heterospecific mobbing calls and the evolution of interspecific social behaviour.
Acknowledgments This work was supported by Grant-In-Aid for JSPS Fellows (SPD: 25-3391). I thank two anonymous referees for their helpful comments on the manuscript.

\section{Compliance with ethical standards}

Ethical notes All experiments were performed in accordance with relevant guidelines and regulations. All experimental protocols were approved by the Animal Care and Use Committees at the Rikkyo University and adhered to the Guidelines for the Use of Animals in Research of the Animal Behavior Society/Association for the Study of Animal Behaviour. This research was performed under permission from the Ministry of the Environment and the Forestry Agency of Japan.

\section{References}

Campobello D, Sarà M, Hare JF (2011) Under my wing: lesser kestrels and jackdaws derive reciprocal benefits in mixed-species colonies. Behav Ecol 23:425-433

Caro T (2005) Antipredator defenses in birds and mammals. University of Chicago Press, Chicago

Cooper WE Jr, Blumstein DT (2015) Escaping from predators: an integrative view of escape decisions. Cambridge University Press, Cambridge

Curio E (1978) The adaptive significance of avian mobbing. I. Teleonomic hypotheses and predictions. Z Tierpsychol 48:175-183

Dominey WJ (1983) Mobbing in colonially nesting fish, especially the bluegill, Lepomis macrochirus. Copeia 4:1086-1088

Flasskamp A (1994) The adaptive significance of avian mobbing. V. An experimental test of the 'move on' hypothesis. Z Tierpsychol 96:322-333

Forsman JT, Mönkkönen M (2001) Responses by breeding birds to heterospecific song and mobbing call playbacks under varying predation risk. Anim Behav 62:1067-1073

Gill SA, Bierema AMK (2013) On the meaning of alarm calls: a review of functional reference in avian alarm calling. Ethology 119:449-461

Graw B, Manser MB (2007) The function of mobbing in cooperative meerkats. Anim Behav 74:507-517

Hurd CR (1996) Interspecific attraction to the mobbing calls of blackcapped chickadees (Parus atricapillus). Behav Ecol Sociobiol 38:287-292

Johnson FR, McNaughton EJ, Shelley CD (2003) Mechanisms of heterospecific recognition in avian mobbing calls. Aust J Zool 51:577-585

Krama T, Krams I (2005) Cost of mobbing call to breeding pied flycatcher, Ficedula hypoleuca. Behav Ecol 16:37-40

Krams I, Krama T (2002) Interspecific reciprocity explains mobbing behaviour of the breeding chaffinches, Fringilla coelebs. Proc Roy Soc Ser B 269:2345-2350

Krams I, Bērzinšs A, Krama T (2009) Group effect in nest defence behaviour of breeding pied flycatchers, Ficedula hypoleuca. Anim Behav 77:513-517

Magrath RD, Haff TM, Horn A, Leonard ML (2010) Calling in the face of danger: predation risk and acoustic communication by parent birds and their offspring. Adv Study Behav 41:187-253

Magrath RD, Haff TM, Fallow PM, Radford AN (2015a) Eavesdropping on heterospecific alarm calls: from mechanisms to consequences. Biol Rev 90:560-586

Magrath RD, Haff TM, McLachlan JR, Igic B (2015b) Wild birds learn to eavesdrop on heterospecific alarm calls. Curr Biol 25:2047-2050 
Mundry R, Fischer J (1998) Use of statistical programs for nonparametric tests of small samples often leads to incorrect $P$ values: examples from Animal Behaviour. Anim Behav $56: 256-259$

Nakagawa S (2004) A farewell to Bonferroni: the problems of low statistical power and publication bias. Behav Ecol 15:1044-1045

Nocera JJ, Taylor PD, Ratcliffe LM (2008) Inspection of mob-calls as sources of predator information: response of migrant and resident birds in the Neotropics. Behav Ecol Sociobiol 62:1769-1777

Nolen MT, Lucas JR (2009) Asymmetries in mobbing behaviour and correlated intensity during predator mobbing by nuthatches, chickadees and titmice. Anim Behav 77:1137-1146

Randler C (2012) A possible phylogenetically conserved urgency response of great tits (Parus major) towards allopatric mobbing calls. Behav Ecol Sociobiol 66:675-681

Randler C, Förschler MI (2011) Heterospecifics do not respond to subtle differences in chaffinch mobbing calls-message is encoded in number of elements. Anim Behav 82:725-730

Randler C, Vollmer C (2013) Asymmetries in commitment in an avian communication network. Naturwissenschaften 100:199-203

R Core Team (2014) R: a language and environment for statistical computing. R Foundation for Statistical Computing, Vienna

Robinson SK (1985) Coloniality in the yellow-rumped cacique (Cacicus cela) as a defense against nest predators. Auk 102:506-519

Sieving KE, Contreras TA, Maute KL (2004) Heterospecific facilitation of forest-boundary crossing by mobbing understory birds. Auk 121:738-751
Suzuki TN (2011) Parental alarm calls warn nestlings about different predatory threats. Curr Biol 21:R15-R16

Suzuki TN (2012a) Referential mobbing calls elicit different predator-searching behaviours in Japanese great tits. Anim Behav 84:53-57

Suzuki TN (2012b) Long-distance calling by the willow tit, Poecile montanus, facilitates formation of mixed-species foraging flocks. Ethology 118:10-16

Suzuki TN (2014) Communication about predator type by a bird using discrete, graded and combinatorial variation in alarm calls. Anim Behav 87:59-65

Suzuki TN (2015) Assessment of predation risk through referential communication in incubating birds. Sci Rep 5:10239

Suzuki TN, Ueda K (2013) Mobbing calls of Japanese tits signal predator type: field observations of natural predator encounters. Wilson J Ornithol 125:412-415

Tamura N (1989) Snake-directed mobbing by the Formosan squirrel Callosciurys erythraeus thaiwanensis. Behav Ecol Sociobiol 24:175-180

Templeton N, Greene E (2007) Nuthatches eavesdrop on variations in heterospecific chickadee mobbing alarm calls. Proc Natl Acad Sci USA 104:5479-5482

Wheatcroft D, Price TD (2013) Learning and signal copying facilitate communication among bird species. Proc R Soc Lond B 280:20123070 